\title{
PARTISIPASI MAHASISWA KULIAH KERJA NYATA TEMATIK WIRA DESA (KKNT-WD) DALAM KEGIATAN MASYARAKAT
}

\author{
Puji Muniarty $^{1 *}$, Wulandari ${ }^{2}$, Nabila Putri Sakinah ${ }^{3}$, Bambang Hermanto $^{4}$, Rifka Annisa ${ }^{5}$ \\ 1, 2, 3, 4, 5 Sekolah Tinggi Ilmu Ekonomi (STIE) Bima, J1 Wolter Monginsidi Kompleks Tolobali, Kota Bima, Indonesia \\ Email: puji.stiebima@gmail.com
}

\begin{abstract}
Real Work Lecture $(K K N)$ is a community empowerment activity by students as a manifestation of the tridharma activities of higher education. Community service activities aim to enable students to implement science and technology as well as skills in the community so that they can become agents of change and sustainable development. The participation of KKN students in community activities plays an important role in the success of work program activities while at the KKN location. This participation can be demonstrated by being directly involved in several preparations for the 76th Independence Day of the Republic of Indonesia held by the Dodu Village Youth Organization. The Bima College of Economics (STIE) with its vision of "Making the Bima College of Economics (STIE) as an educational institution that prints ready-to-use Human Resources and has an entrepreneurial spirit". The spirit of entrepreneurship is interpreted as working without being ordered so that self-awareness is needed here in carrying out various activities. It is evident that the participation of students from various community activities for KKNT-WD STIE Bima students is very high, it is clearly seen from their direct involvement in measuring and cleaning the volleyball field and mutual cooperation in cleaning the surrounding environment.
\end{abstract}

Keywords: Community Service Program; Community Activities; Participation.

\begin{abstract}
ABSTRAK
Kuliah Kerja Nyata (KKN) merupakan kegiatan pemberdayaan masyarakat oleh mahasiswa sebagai perwujudan kegiatan tridharma perguruan tinggi.Kegiatan KKN bertujuan agar mahasiswa dapat megimplementasikan ilmu pengetahuan dan teknologi serta keterampilan dimasyarakat sehingga dapat menjadi agen perubahan dan pembangunan yang berkelanjutan. Partisipasi mahasiswa KKN dalam kegiatan masyarakat sangat berperan penting dalam keberhasilan kegiatan program kerja selama berada dilokasi KKN. Partisipasi itu dapat ditunjukkan dengan melibatkan diri secara langsung ke beberapa kegiatan persiapan penyambutan kemerdekaan RI ke-76 yang di adakan oleh karang taruna kelurahan Dodu. Sekolah Tinggi Ilmu Ekonomi (STIE) Bima dengan visinya yaitu "Menjadikan Sekolah Tinggi Ilmu Ekonomi (STIE) Bima sebagai lembaga pendidkkan yang mencetak Sumber Daya Manusia siap pakai dan berjiwa entrepreneurship". Jiwa entrepreneurship dimaknakan sebagai bekerja tanpa diperintah sehingga disini diperlukan kesadaran diri dalam melaksanakan berbagai aktivitas. Hal ini terbukti bahwa partisipasi mahasiswa dari berbagai kegiatan kemsayarakatn mahasiswa KKNT-WD STIE Bima sangat tinggi terlihat jelas dari terjun langsung mereka dalam pengukuran dan pembersihan lapangan volly ball dan gotong royong pembersiapan lingkungan sekitar.
\end{abstract}

Kata kunci: Kuliah Kerja Nyata; Kegiatan Masyarakat; Partisipasi.

\section{PENDAHULUAN}

Berdasarkan Undang-Undang Republik Indonesia Nomor 12 Tahun 2012 tentang Pendidikan Tinggi pasal 1 ayat 9 menyatakan bahwa Tridharma adalah kewajiban Perguruan 
Tinggi untuk menyelenggarakan Pendidikan, Penelitian dan Pengabdian Kepada Masyarakat. Kemudian dijelaskan pula pada ayat 11 bahwa pengabdian kepada masyarakat adalah kegiatan sivitas akademika yang memanfaatkan Ilmu Pengetahuan yang memanfaatkan Ilmu Pengetahuan dan Teknologi untuk memajukan kesejahteraan masyarakat yang mencerdaskan kehidupan bangsa. Pada perguruan Tinggi pelaksanaan dapat dilakukan melalui Kuliah Kerja Nyata $(\mathrm{KKN})$.

Menurut (Aristoteles, 2017) Kuliah Kerja Nyata (KKN) adalah kegiatan pemberdayaan masyarakat oleh mahasiswa sebagai perwujudan kegiatan tridharma perguruan tinggi. dan wajib diikuti oleh semua mahasiswa Program Strata Satu (S-I) yang ada di Sekolah Tinggi Ilmu Ekonomi (STIE) Bima. Visi Sekolah Tinggi Ilmu Ekonomi (STIE) Bima yaitu "Menjadikan Sekolah Tinggi Ilmu Ekonomi (STIE) Bima sebagai lembaga pendidkkan yang mencetak Sumber Daya Manusia siap pakai dan berjiwa entrepreneurship". Jiwa entrepreneurship dimaknakan sebagai bekerja tanpa diperintah sehingga disini diperlukan kesadaran diri dalam melaksanakan berbagai aktivitas. Ditahun 2021 Sekolah Tinggi Ilmu Ekonomi (STIE) Bima melaksanakan Kuliah Kerja Nyata (KKN) di VIII (Delapan) titik lokasi baik yang berada di Kota Bima maupun Kabupaten Bima salah satunya di Kelurahan Dodu Kecamatan Rasanae Timur. Kecamatan RasanaeTimur merupakan salah satu Kecamatan tertua yang ada Di Kota Bima dan termasuk sentra pertanian dan ditetapkan sebagai kawasan pertanian dengan lahan basah yang saat ini sudah memiliki prasarana irigasi dan kemampuan lahan yang dapat dimanfaatkan untuk pengembangan tanaman pangan (padi) dengan luas 463ha dan kawasan peternakan dalam rangka mendukung program Buni Sejuta Sapi (BSS) dan pengelolaannya dilakukan dengan cara peningkatan jumlah ternak, penggemukan ternak, pembibitan ternak, penyediaan pakan ternak, dan pengembangan industri pengolahan hasil ternak sehingga dapat menghasilkan komoditi unggulan sapi. Kuliah Kerja Nyata dilaksanakan guna meningkatkan relevansi pendidikan tinggi dengan kbutuhan masyarakat sekaligus membantu masyarakat melancarkan pembangunan di lokasi KKN dilaksanakan.

Menurut (Budimansyah, D., Ruyadi, Y,. \& Rusmana, 2010) kegiatan kegiatan KKN merupakan sebuah kesempatan bagi mahasiswa mengaplikasikan iptek dan KKN tematik merupakan salah satu model dalam mengembangkan pendidikan karakter di perguruan tinggi. Kuliah Kerja Nyata (KKN) Tematik yang dilaksanakan oleh Sekolah Tinggi Ilmu Ekonomi (STIE) Bima yaitu Kuliah Kerja Nyata Tematik Wira Desa (KKNT-WD) dengan tujuan (1) membantu menemukan solusi permasalahan UMKM (2) memperoleh database potensi wirausaha desa, (3) menunbuhkan wirausaha baru/ starup desa dan mengembangkan osaha potensial desa dan (4) menjadikan desa potensi starup desa sebagai desa binaan dengan berkerja sama dengan masyarakat, pemerintah daerah/ desa serta stakeholder. Peserta KKNT-WD STIE 
Bima ditempatkan pada 8 (delapan) lokasi yang tersebar di daerah kota bima dan kabupaten bima serta terdiri dari berbagai konsentrasi disiplin ilmu yaitu konsentrasi manajemenn keuangan, manajemen pemesaran dan manajemen sumber daya manusia. Dari 8 (Delapan) lokasi yang sudah ditentukan salah satunya yaitu di Kecamatan Rasanae Timur Kelurahan Dodu. Dalam pelaksanaan program kerja selama dilapangan tentunya akan disesuaikan dengan tema KKNT-WD dan situasi serta kebutuhan masyarakat setempat dalam proses wira desa serta berbasis riset. Sehingga mengharuskan peserta KKN untuk mensurvei pendataan potensi desayang akan dijadikan sebagai sasaran dan program kerja mahasiswa kuliah kerja nyata.

Melalui KKNT-WD diharapkan dapat meningkatkan kerjasama yang saling menguntungkan antara kembaga pendidikan tinggi dengan pemerintah daerah (sinergi pemberdayaan potensi-potensi masyarakat) untuk peningkatan keterampilan kelompok sasaran dalam melakukan identifikasi potensi. permasalahan dan peluang pengembangan usaha, menyusun rencana kegiatan, melakukan impelementasi kegiatan, monitoring dan evaluasi program serta keterlibatn partisipasi mahasiswa dalam berbagai kegiatan masyarakat setempat. Dalam memeriahkan perayaan 17 Agustus 2021 pihak karang taruna desa Dodu mengalami kesulitan tenaga dalam menyongsong menyambut guna merayakan hari kemerdekaan RI KE-76. Melalui rapat koordinasi pihak karang taruna meminta partisipasi mahasiswa Kuliah Kerja Nyata untuk terlibat dalam kegiatan Dirgahayu Republik Indonesia ke-76. Dengan antusias yang tinggi mahasiswa KKN dengan senang hati berpatisipasi aktif dalam kegiatan tersebut dengan membantu dsalam pengecatan lapangan, gotong royong lingkungan sekitar dan mengikuti upacara proklmasi kemerdekaan di kelurahan dodu bersama pemerintah daerah setempat.

\section{METODE}

Metode yang dilakukan dalam pengabdian ini yaitu dengan metode partisipasi. Menurut Theodorson dalam Mardikanto (1994) mengemukakan bahwa dalam pengertian sehari-hari, partisipasi merupakan keikutsertaan atau keterlibatan seseorang (individu atau warga masyarakat) dalam suatu kegiatan tertentu. Keikutsertaan atau keterlibatan mahasiswa Kuliah Kerja Nyata didalam kegiatan masyarakat dilaksanakan pada tanggal 15-17 Agustus 2021. Peserta partisipasi kegiatan kemasyarakatan yaitu karang taruna, masyarakat, mahasiswa kkn dan pemerintah daerah setempat. Sebelum kegiatan dilaksanakan pihak karang taryuna dan masyarakat setempat melakukan rapat koordinasi dan dilakukan pembagian tugas kegiatan termasuk bagian tugas kegiatan yang akan dilakukan oleh mahasiswa KKNT-WD STIE Bima. Sebelum melaksanakan kegiatan dilapangan dalam rangka menyambut hari kemerdekaan RI Ke- 76 ketua kelompok KKN Dodu melakukan briefing kepada anggota KKN terkait pembagian tugas dilapangan. 


\section{HASIL DAN PEMBAHASAN}

Mahasiswa kuliah kerja nyata sebelum diterjunkan ke lokasi sebelumnya sudah dibekali dengan pembekalan Kuliah Kerja Nyata dengan pemateri yang sudah ditunjuk dengan Surat Keputusan Sekolah Tinggi Ilmu Ekonomi (STIE) Bima. Pembekalan ini merupakan bagian penting dalam kegiatan KKN Tematik Wira Desa, sebagaimana dikatakan (Wagiran, Istanto Wahyu Djatmiko, Sukardi, 2011) kesuksesan pelaksanaan kegiatan KKN Tematik bagi mahasiswa sangat dipengaruhi oleh pembekalan yang nereka terima. Pembekalan dilakukan selama 2 (dua) hari dengan materi yang berbeda sesuai dengan kebutuhan kegiatan dilapangan dan bertempat di Auditorium STIE Bima. Seluruh mahasiswa peserta KKNT-WD yang berjumlah 244 orang yang dibagi dalam berbagai sheet selama pelaksanaan pembekalan berlangsung. Materi-materi yang disampaikan oleh masing-masing pemateri dikemas sesimpel mungkin dan mudaj duimengerti serta diimplementasikan oleh peserta KKN selama berada dilokasi. Setiap diakhir materi mahasiswa diberikan kesempatan untuk bertanya dan mendiskusikan hal-hal yang kemungkinan yang akan menjadi kendala dalam melaksanakan program kerja dilapangan.

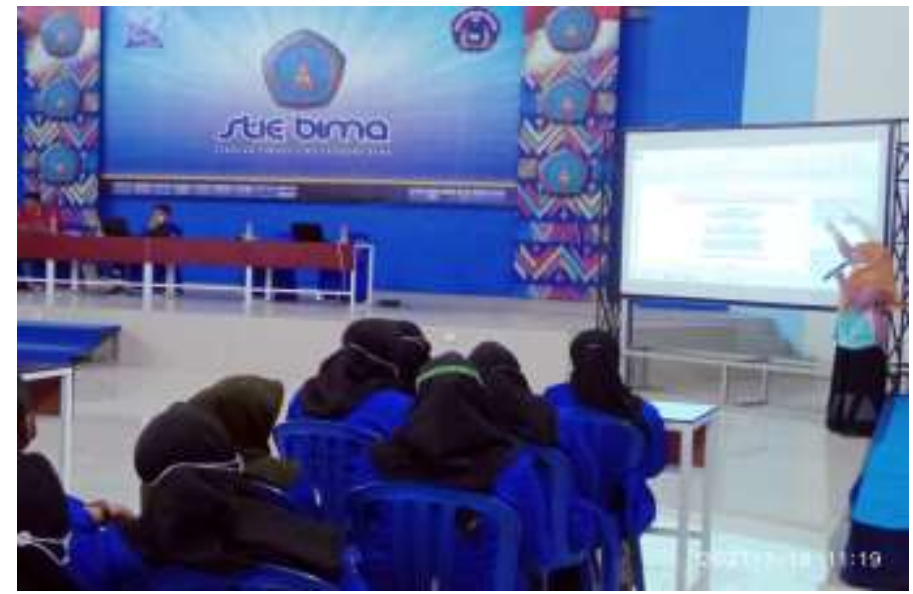

Gambar 1. Pemateri Pembekalan KKNT-WD "Publikasi Kuliah Kerja Nyata”

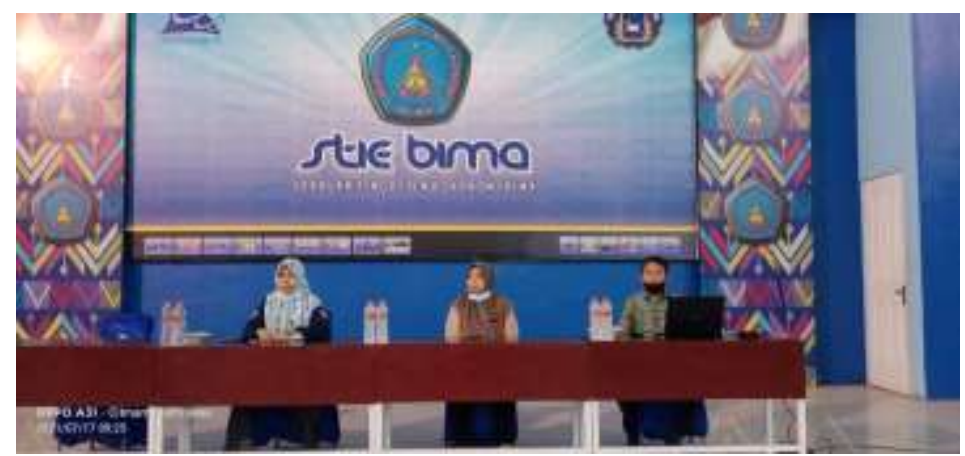

Gambar 2. Pemateri Pembekalan KKNT-WD "Konsep KKNT-WD \& Pemberdayaan Masyarakat" 


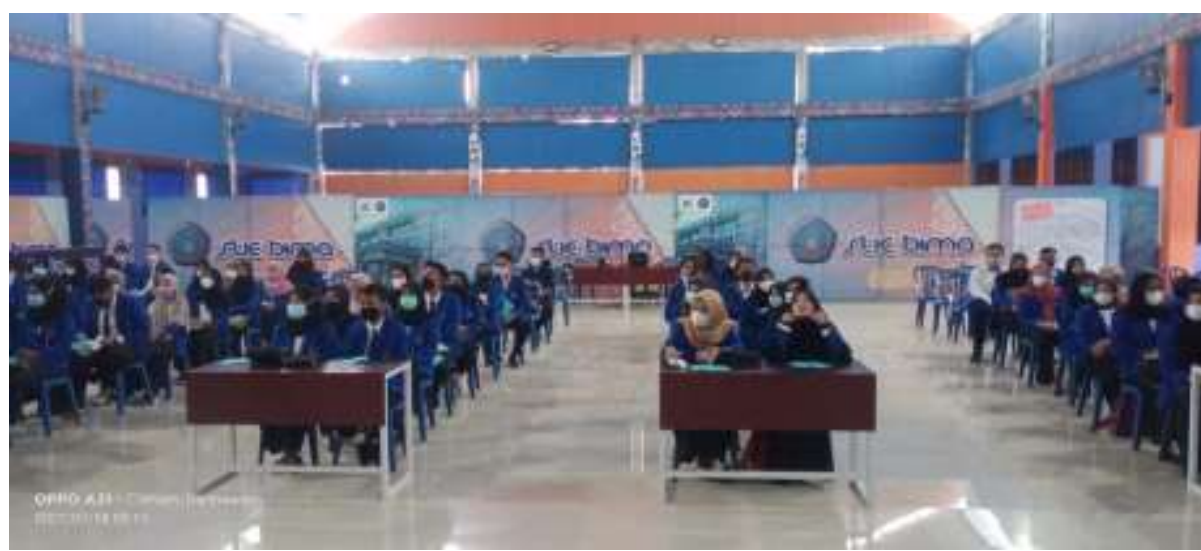

Gambar 3. Mahasiswa peseerta KKNT-WD

Dalam kegiatan kemasyarakatan pendekatan yang digunakan mahasiswa KKNT-WD yaitu dengan metode pendekatan secara partisipatif langsung. Pendekatan ini memiliki peluang untuk mengembangkan dan menjamin suatu komunitas sosial yang memungkinkan terjadinya proses belajar dari masyarakat untuk beradaptasi dan berintegrasi dengan lingkungannya. Melalui metode ini sangat efektif dilakukan dengan begitu jika ada setiap kegiatan masyarakat mahasiswa kuliah kerja nyata dengan terbuka tanpa diperintah bisa berkolaborasi langsung dengan kegiatan yang ada. Dengan begitu akan terjalin kerjasama dan tali silaturahmi antara masyarakat dengan mahasiswa KKN. Partisipasi mahasiswa kuliah kerja nyata dalam kegiatan penyambutan kemerdekaan RI ke-76 dikelurahan Dodu yaitu mahasiswa turut serta dalam pembersihan gotong royong lingkungan sekitar, pengukuran area lapangan termasuk pencecatan lapangan dan upacara bersama pemerintah setempat. Hal ini terlihat sebelum kegiatan berlangsung dilaksanakan rapat koordinasi oleh pihak karang taruna dengan mahasiswa KKNTWD guna membahas hal-hal apa saja yang perlu dilakukan guna merayakan dirgahayu RI ke-76. Tingkat partisipasi mahasiswa sangat tinggi dengan ditandai sebelum pelaksanaan kegiatan ketua kelompok kkn melalukan briefing guna memberikan pengarahan dan pembagian anggota untuk beberapa kegiatan. Hasil menunjukkan lingkungan sekitar bersih, lapnagan terukur dengan baik serta dapat melaksanakan upacara 17 Agustus 2021 dengan para siswa dan pemerintah setempat. 


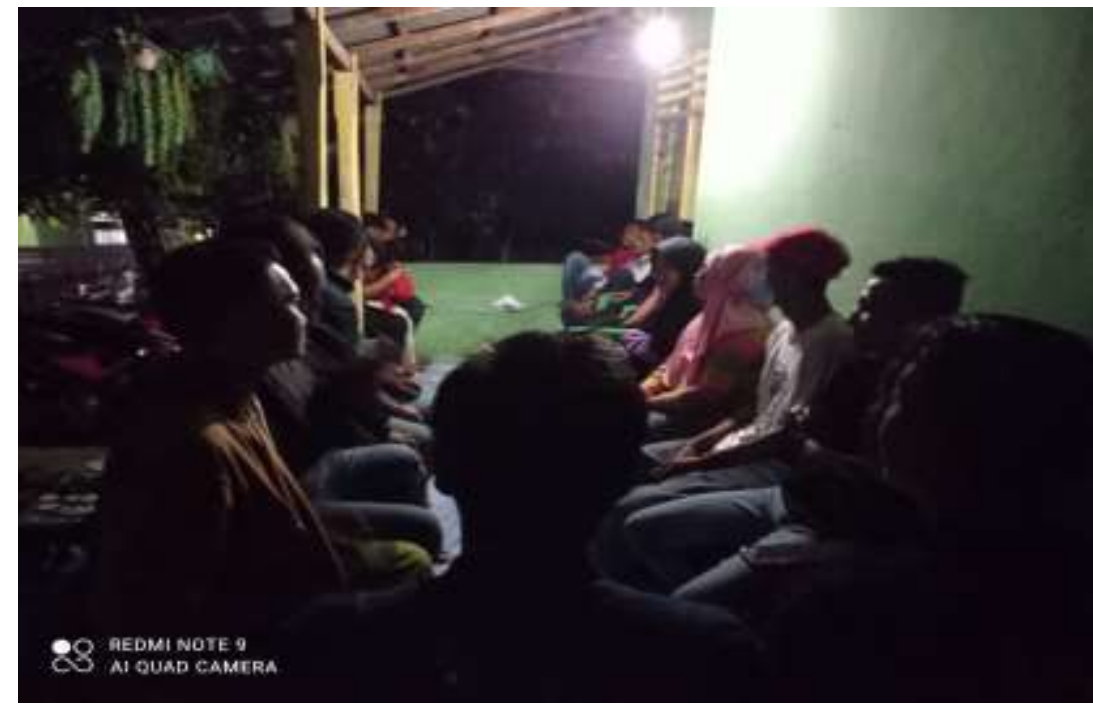

Gambar 4. Rapat Koordinasi Dengan Karang Taruna

Dalam hal ini mahasiswa KKN-WD bersama karang taruna kelurahan dodu mengadakan rapat dan diskusi bersama berkaitan dengan beberapa persiapan dan pembagian tugas dalam berbagai kegiatan di desa dalam penyambutan hari kemerdekaan RI ke-76. Ketua karang taruna berserta anggota membagi tugas dan jadwal kegiatan lomba yang melibatkan mahasiswa KKN-WD. Dengan begitu diharapkan dari kolaborasi ini dapat memperlancar kegiatan vollyball dan kegiatan lain yang berlangsung.

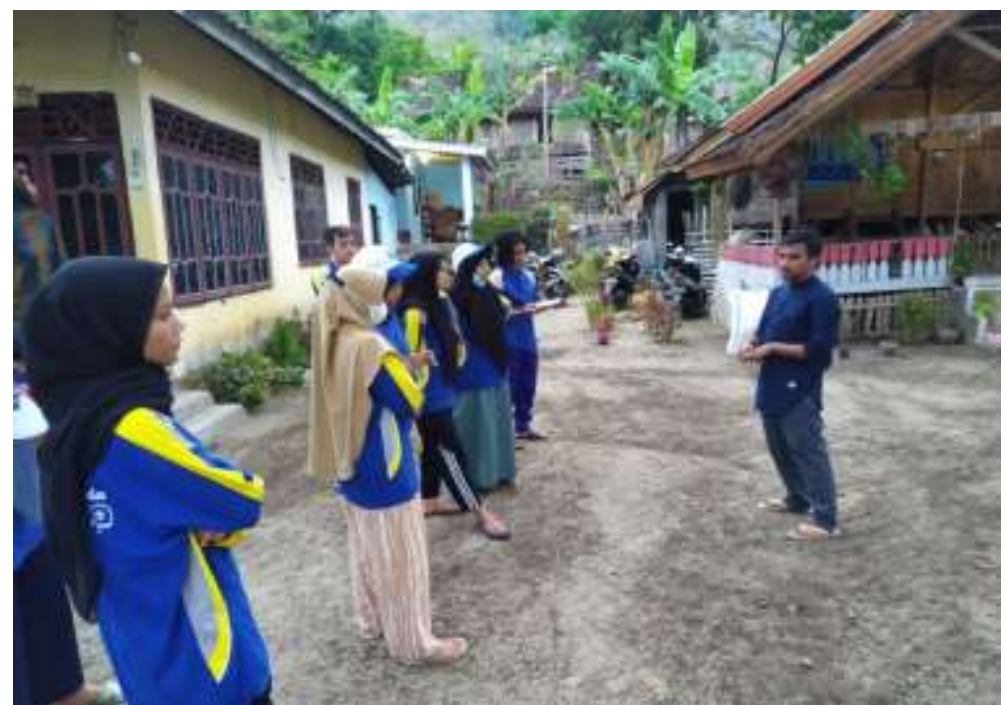

Gambar 5. Briefing Ketua Kelompok KKN

Sebelum memulai berbagai kegiatan dan aktivitas Ketua kelompok KKN memberikan pengarahan ke para anggota kelompok agar dalam pelaksanaan kegiatan yang telah 
direncanakan pada time schedule KKN-WD dapat berjalan sesuai dengan yang diharapkan. Setiap kegiatan yang dilakukan oleh masing-masing divisi akan dilaporkan dan dibuktikan dengan dokumentasi kegiatan. Hal ini diarahkan oleh ketua kelompok agar masing-masing divisi memiliki rasa tanggung jawab akan tugas yang telah disepakati bersama.

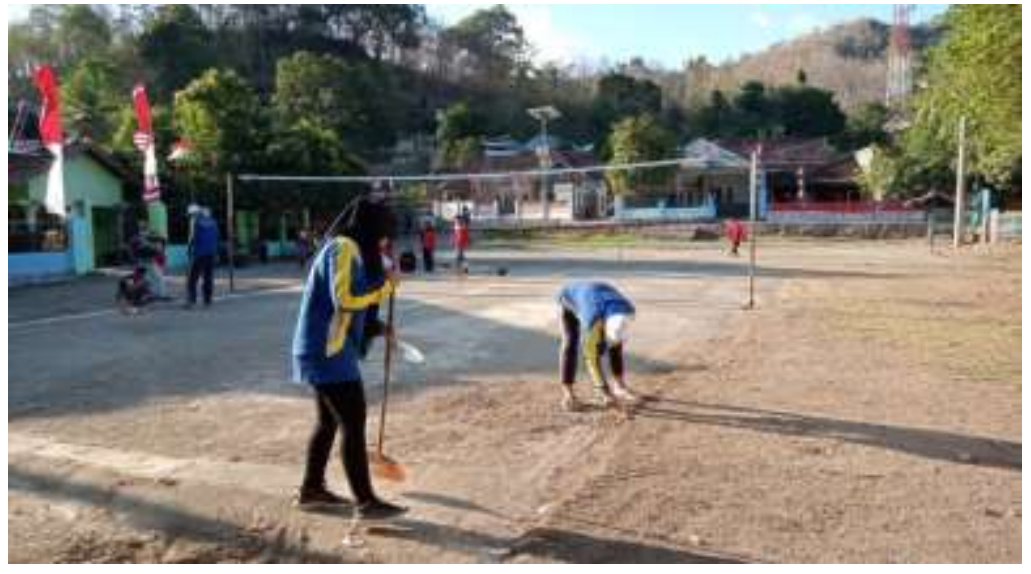

\section{Gambar 6. Pengukuran Dan Pembersihan Lapangan Volly Ball}

Mahasiswa KKN-WD bekerja sama dengan karang taruna lingkungan Dodu dalam kegiatan pemebersihan dan pemgukuran garis lapangan volly ball. Dalam ha ini juga mahasiswa KKN ditunjuk sebagai hakim garis selama pelaksanaan lomba volly ball. Sehingga dalam hal ini tercipta persatuan yang semakin erat antara mahasiswa KKN, karang taruna, dan seluruh masyarakat kelurahan dodu.

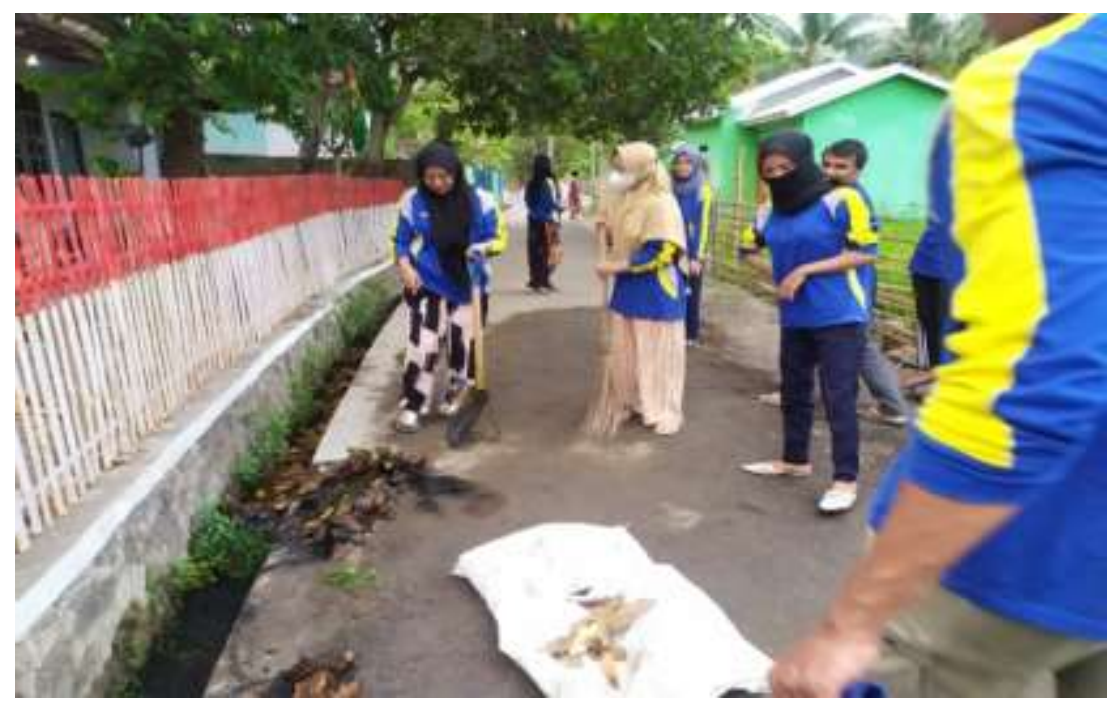

Gambar 7. Gotong Royong Lingkungan Sekitar

Kegiatan gotong royong ini merupakan kegiatan yang telah disusun bersama oleh mahasiswa KKN-WD sebagai kegiatan penunjang selama pelaksanaan KKN dilokasi. Kegiatan 
ini dilakukan untuk membantu masyarakat sekitar demi terciptanya lingkungan yang bersih dan asri. Dari kegiatan ini mahasiswa KKN dapat menjalin hubungan yang erat dengan warga masyarakat Kelurahan Dodu.

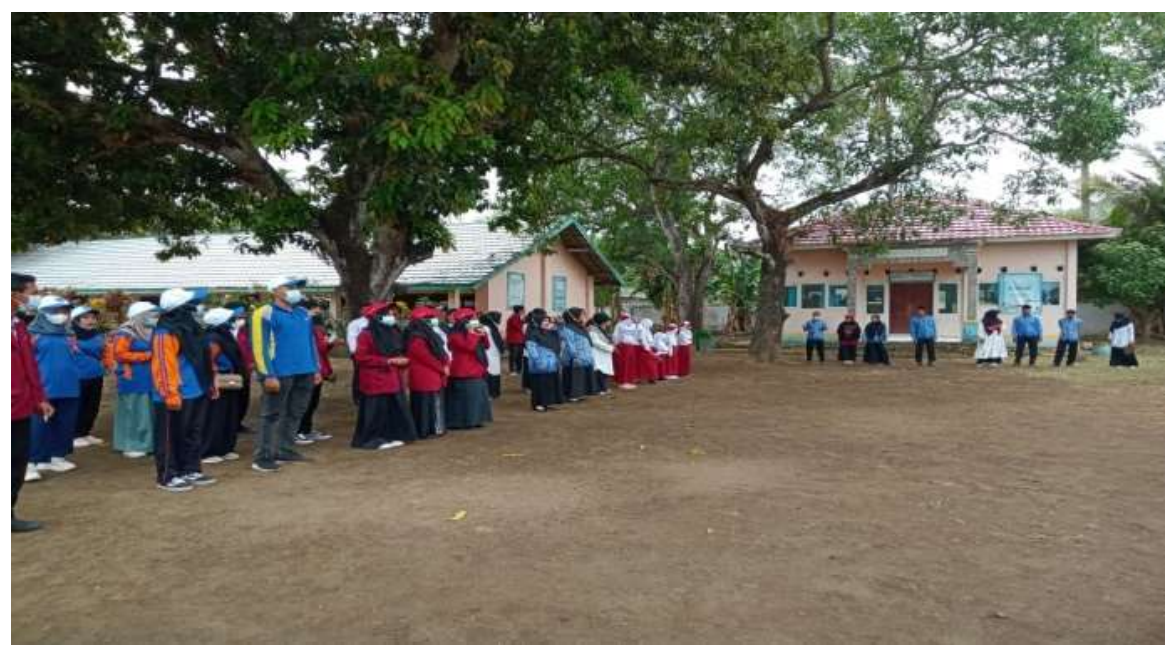

Gambar 8. Upacara 17 Agutsus 2021

Partisiapasi yang dilakukan oleh mahasiswa KKN-WD dalam memperingati HUT Kemerdekaan Republik Indonesia yang ke-76 PADA TANGGAL 17 Agustus 2021 merupakan kegiatan yang sudah dirancang bersama dengan pemerintah desa Kelurahan Dodu sehingga mahasiswa kkn menjadi partisipan dalam upacara hari kemerdekaan. Sehingga dari sini tercipta persatuan yang semakin erat antara seluruh anggota pemerintah keluran dodu dan siswa-siswi serta mahasiswa KKN selain STIE Bima menuju indonesia unggul.

\section{KESIMPULAN}

Dalam kegiatan partisipasi mahasiswa KKNT-WD dalam kegiatan masyarakat di Kelurahan Dodu Kecamatan Rasanae Timur sangat tinggi hal ini terbukti dengan hadirnya mahasiswa di dalam rapat persiapan penyambutan memperingari dirgahayu RI ke-76 yang diadakan oleh karang taruna dan terliabtanya langsung mereka dalam pengukuran dan pemebrsihan lapangan volly, gotong royong lingkungan sekitar dan hadir dalam upacara 17 agustus 2021. Ini menunjukkan bahwa tingkat partisipasi mahasiswa kuliah kerja nyata untuk terlibat langsung ke dalam kegiatan masyarakat sangat tingggi dan mereka cukup cepat beradaptasi dengan masyarakat setempat. Saran daripada kegiatan pengabdian ini yaitu diharapkan kepada mahasiswa kuliah kerja nyata wiradesa kedepan labih baik lagi dalam mendata potensi desa dan menyusun secara maksinal untuk kegiatan penunjang KKN yang yang berkaitan kegiatan dikemasyarakatan dan diharapkan kepada warga setempat untuk tidak membuang sampah disembanrang tempat. 


\section{DAFTAR PUSTAKA}

Anwas, O. M. (2011). Kuliah Kerja Nyata Tematik Pos Pemberdayaan Keluarga Sebagai Model Pengabdian Masyarakat Di Perguruan Tinggi. Jurnal Pendidikan Dan Kebudayaan, 17(5), 565.

Aristoteles, D. H. P. (2017). Pengembangan Sistem Pelaporan Kegiatan KKN. Jurnal Komputasi, 5(1), 8-16.

Budimansyah, D., Ruyadi, Y,. \& Rusmana, N. (2010). Model Pendidikan Karekter di Perguruan Tinggi. Universitas Pendidikan Indonesia.

Hidayat, N. (2019). Model Kuliah Kerja Nyata (KKN) Integratif Interkonektif Berbasis pada Pengembangan Masyarakat yang Produktif Inovatif dan Kreatif. Panangkaran: Jurnal Penelitian Agama Dan Masyarakat, 2(2), 219.

Rostinawati, T., Si, M., Maharani, R., Si, M., Mitha, S. R., Si, S., Dipa, D., Padjadjaran, U., \& Keputusan, S. (2009). Pengembangan Model Pendekatan Partisipatif dalam Memberdayakan Masyarakat Miskin Kota Medan Untuk Memperbaiki Taraf Hidup. Penelusuran Senyawa Aktif Ekstrak Daun Sukun (Artocarpus Altilis) Terhadap Staphylococcus Aureus, Microsporum Gypseum Dan Candida Albicans Oleh, NOVEMBER, 1-107.

Sulastri, R. E., Ananto, R. P., \& Haslina, W. (2020). Pengelolaan Keuangan Dan Pemasaran Pada Kelompok Usaha Bersama (Kube) “Zaizha. 2(2), 86-90.

Suswandari, M., \& Widayanti, E. D. (2021). Pemberdayaan Rumah Cerdas Univet (Rcu) Bunayya Di Desa Jetis Sukoharjo. Jurnal Warta Desa (JWD), 3(1), 62-69.

Tjandi, Y. (n.d.). Pemberdayaan Remaja Karang Taruna dan Masyarakat Melalui Keterampilan IT dan ARTL Guna Menumbuhkembangkan Usaha Kreatif Lokal Di Desa Mandalle Pangkep untuk meningkatkan Pendapatan Keluarga. 2015, 698-702.

Wagiran, Istanto Wahyu Djatmiko, Sukardi, B. L. (2011). KEWIRAUSAHAAN DI SMK Wagiran, Istanto Wahyu Djatmiko, Sukardi, Barkah Lestari Abstrak. III, 1-7.

Undang-Undang Republik Indonesia Nomor 12 Tahun 201210 Agustus 2012 tentang Pendidikan Tinggi 